Article

\title{
Unnatural Technology in a "Natural" Practice? Human Nature and Performance-Enhancing Technology in Sport
}

\section{Francisco Javier Lopez Frias}

Kinesiology Department and Rock Ethics Institute, The Pennsylvania State University, University Park, PA 16801, USA; fj113@psu.edu

Received: 15 April 2019; Accepted: 20 June 2019; Published: 26 June 2019

\begin{abstract}
Background: The World Anti-Doping Agency (WADA) utilizes three criteria to include a technology in the List of Banned Substances and Methods-performance enhancement, health, and the spirit of sport. The latter is arguably the most fundamental one, as WADA justifies the anti-doping mission by appealing to it. (2) Method: Given the interrelationship among the notions of "human nature," "natural talent," and "sport," I investigate what view of human nature underpins the "spirit of sport" criterion. To do so, I focus on both WADA's official documents and scholarly formulations of the spirit of sport (that align with that of WADA). (3) Results: I show that the value attributed to excellence and effort in WADA's formulation of the "spirit of sport" criterion has its roots in the notion of human nature of the work ethic that resulted from the secularization of the Protestant ethic. (4) Conclusion: Drawing on my analysis of the "spirit of sport" criterion, I pose critical questions concerning the justification of WADA's anti-doping campaign and a tentative solution to move forward in the debate.
\end{abstract}

Keywords: sport ethics; technology; the spirit of sport; excellence; anti-doping; nature

\section{Introduction: Naturalness, Perfectibility, and Anti-Doping. Three Strongly Related Concepts}

In Defining Reality: Definitions and the politics of meaning, Edward Schiappa [1] (p. 21), argues that concepts are like "road maps" that help to navigate reality by presenting it in a specific way. Concepts strongly influence how individuals experience and deal with the world. Thus, despite often being regarded as a purely theoretical task, the tasks of clarifying and defining concepts have tremendous practical consequences. In Schiappa's words, "the act of defining [has] ethical and normative ramifications" [1] (p. 3). Definitions guide humans' action in two ways: Individually and collectively. From an individual standpoint, they serve to categorize objects and phenomena in the world and know what to expect from them (e.g., the category "fire" includes the aspect of being harmful). Collectively speaking, concepts provide shared understandings that enable communication and facilitate social cooperation.

Given the practical implications of definitions, it could be argued that the more foundational the concept, the higher its practical and theoretical impact. One such foundational concept is "human nature." By analyzing the different uses of the concept of "the natural" in public debates, the Nuffield Council on Bioethics' analysis paper, "(un)naturalness," states that the concept has become a rhetorical tool that acts as a placeholder for a range of values and concerns that are meaningful and important to people [2]. Thus, the definition of "the natural" has significant theoretical and practical ramifications. Its implications can be observed in the medical practice, where the concept of "human nature" heavily influences those of "health" and "medicine." In shamanic culture, for instance, the body is characterized as a recipient of energy, a healthy state is determined by the correct flow of energy throughout the 
body, and medicine is the art to secure and restore the body's energy flow. In modern society, where human nature is defined materialistically by appealing to a series of biological elements (i.e., heart, lungs, veins, genes, and neurons) and functions (i.e., respiration, blood flow, digestion, and neuronal activity), health is regarded as the natural functioning of the body, and medicine as the art of restoring humans' bodily functioning to its natural levels.

Similarly, in the debate on the ethics of performance-enhancing technology, the notion of "the natural" informs the concept of "sport," which, in turn, determines how sports are regulated to protect and promote their essential values. For instance, Sigmund Loland and Mike McNamee identify two views of human nature (and sport) in the debate, namely: Restrictive and permissive, and argue that, "The dominant or official public sport policy response ... is [the] restrictive one" [3] (p. 117). Proponents of the "permissive" view of sport take the defining character of sport to be the empowerment of individuals as autonomous and responsible agents [4]. In a more extreme version of this approach, sport is regarded as an arena for humans to push human limits further $[5,6]$. Thus, in these conceptions of sport, the exercise of freedom is the defining trait of human nature. They build upon the idea that to be human is to exercise freedom. From an ethical standpoint, actions that protect and foster freedom are accepted. In contrast, those that limit the exercise of freedom are condemned. Permissive sport philosophers, therefore, advocate for relaxing or, in some cases, removing the ban on doping because it limits athletes' freedom and possibilities to enhance themselves.

From a restrictive perspective, sport, "is a sphere of ethically admirable human excellence" [3] (p. 117). Restrictive approaches to sport draw on a teleological Aristotelian understanding of human nature grounded in the principle that all entities are, by nature, oriented towards a goal or purpose, namely, the actualization of their potentialities. For instance, a seed has the potential to develop into a plant. From an ethical perspective, in teleological accounts of human nature, the actualization of potentialities and moral value are intertwined. Thus, a seed is good when it becomes a plant and bad when it fails to do so. The same logic applies to human beings. Humans, as natural beings, also gravitate towards the goal of actualizing their potential. Ethically speaking, the realization of their natural potentialities leads to good action or, more broadly speaking, good life.

In Loland and McNamee's words, the search for "perfectibility" defines humans. Human activities, including sport, are "exponent[s] of human excellence [or perfectibility]" [3] (p. 118). In alignment with this, they argue that what helps humans develop their potential is morally acceptable, whereas what undermines it is condemnable. Therefore, they consider doping to be morally wrong because it provides a shortcut to the development of physical talents. That is to say, doping allows athletes to perform better by bypassing the natural and virtuous way of developing their talents. Doped athletes, thus, might achieve higher levels of performance, but they are not excellent. For such higher levels have been reached through corrupt means. As it was stated above, the restrictive approach to human nature and sport underpins anti-doping policy. For instance, the World-Anti Doping Agency (WADA) justifies its mission based on the preservation of sport as a "pursuit of human excellence through the dedicated perfection of each person's natural talents" [7] (p. 14) ${ }^{1}$. Hence, an analysis of the notion of human nature at the root of WADA's mission is critical to understand anti-doping more fully.

In this article, following the methodology deployed in the Nuffield Council of Bioethics' analysis paper mentioned above, I explore the public debate on doping in order to locate the values at the core of the restrictive view of human nature and sport. To do so, I examine WADA's justification of anti-doping (Section 2). Then, I analyze the work of philosophers who have assisted WADA in formulating it (Section 3). After having identified the worldview that grounds the justification for anti-doping, I explore the connections and similarities between the anti-doping movement and the work ethic that resulted from the secularization of the Protestant ethic (Section 4). Next, I pose critical

1 It must be noted that by "sport" here I mean professional, elite-level sport. For this is the type of sport most affected by WADA's anti-doping regulation. 
questions regarding the Protestant, work-based philosophical notion of human nature underpinning the anti-doping initiative and briefly propose a tentative way to move forward in the debate (Section 5). I conclude with a summary of the main points made throughout the article (Section 6).

\section{The View of the Spirit of Sport at the Heart of WADA}

The concept of the "spirit of sport" is central in anti-doping policy. To evaluate the inclusion of a substance or method within the List of Prohibited Substances and Methods (List), WADA draws on the following three criteria:

4.3.1.1 Medical or other scientific evidence, pharmacological effect or experience that the substance or method, alone or in combination with other substances or methods, has the potential to enhance or enhances sport performance;

4.3.1.2 Medical or other scientific evidence, pharmacological effect or experience that the use of the substance or method represents an actual or potential health risk to the Athlete;

4.3.1.3 WADA's determination that the Use of the substance or method violates the spirit of sport. [7] (p. 30)

For a substance or method to be included on the List, it must meet at least two of the criteria above. However, it could be argued that the "spirit of sport" criterion is more fundamental than the other two. For, in the World Anti-Doping Code (Code), it is declared that, "Doping [must be fought because it] is fundamentally contrary to the spirit of sport." [7] (p. 14). Thus, WADA not only locates the spirit of sport at the heart of anti-doping but also utilizes it to justify the anti-doping campaign. In the Code, the spirit of sport is referred to as "what is intrinsically valuable about sport" [7] (p. 14) and further characterized as follows:

- "the pursuit of human excellence through the dedicated perfection of each person's natural talents;"

- "it is the essence of Olympism;"

- "how we play true;"

- " "the celebration of the human spirit, body and mind," and;

- "reflected in values we find in and through sport, including: Ethics, fair play and honesty; Health; Excellence in performance; Character and education; Fun and joy; Teamwork; Dedication and commitment; Respect for rules and laws; Respect for self and other Participants; Courage; [and] Community and solidarity." [7] (p. 14, my emphasis).

The characterizations of the "spirit of sport" principle above indicate that the anti-doping movement pivots around the terms "natural," "talent," excellence," "perfection," and "commitment (effort)." Ultimately, WADA's attempt to pin down the nature of the spirit of sport is an effort to respond to the classic sport philosophical questions "What is sport?" and "What is the meaning of sport?"2. The Olympic Charter, which is cited in the Code as an illustration of the spirit of sport, contains answers to those questions:

Olympism is a philosophy of life, exalting [(or perfecting)] and combining in a balanced whole the qualities [(or natural talents)] of body, will and mind. Blending sport with culture and education, Olympism seeks to create a way of life based on the joy of effort, the educational value of good example, social responsibility and respect for universal fundamental ethical principles. [8] (p. 11, my emphasis)

2 Or, better said, "What is the significance of competitive sport?" For the anti-doping campaign centers on controlling the use of banned substances in elite-level sport competitions. Only in the last decade, the use of performance-enhancing technology has been regarded as a public health problem and tackled at the amateur and non-competitive level in some countries. 
In Olympism, providing individuals with the experience of joy in the effort to perfect natural talents is the primary function of sport. As WADA resulted from a 50/50 effort between the International Olympic Committee (IOC) and national governments, the Olympic ideals substantially shaped anti-doping. Sport officials and athletes who sympathize with WADA's anti-doping campaign usually appeal to effort to justify the ban on performance-enhancing technology. For instance, swimmer Matt Dunn, who was appointed as member of WADA's Athlete Committee in 2011, argues that, "Some sportsmen and women take drugs to try and cheat their way on to an Olympic team or to a medal at the Games, rather than relying on hard work and natural talent" [9]. Likewise, in an interview published in WADA's website, Olympic medalist Koji Murofushi, argues, "there are no short cuts in life" [10]. For him, success in the sport arena must be achieved through natural talent and many hours of hard work.

For anti-doping advocates, the ban on performance-enhancing technology is justified because it protects the nature of sport by ensuring that sport performance results from effort in cultivating natural talent. Effortless performances are viewed with suspicion. However, the mere appeal to effort and talent is insufficient to justify the anti-doping campaign. The value of both effort and natural talent must be clarified and specified. Why are both elements so significant in elite competitive sport? More importantly for the topic discussed in this article, what confers moral value to effort and natural talent? To tackle these issues, in the next section, I will examine philosophical views of sport, with a significant presence in public discourse, that justify the value of effort and natural talent in competitive sport.

\section{Scholarly Interpretations of the "Spirit of Sport" Principle: Superior Inborn Talents and Work Ethics}

The value of effort and natural talent in sport is pivotal in the work of sport philosophers Thomas H. Murray [11], Michael J. McNamee [12], and Sigmund Loland [13], who have shaped the public debate on doping through their collaboration with WADA and scholarly work. For instance, the three philosophers are listed as the experts on sport enhancement of The Hastings Center [14] and McNamee and Loland serve in the WADA Ethics Panel [15]. To be fair, these authors also consider other normative elements related to anti-doping, such as the right to privacy, equality, and physical integrity $[3,16]$. However, for the purposes of this paper, I focus on their analysis of the spirit of sport, that is, the normative elements intrinsic to sport that must be protected and promoted.

For Murray, "The glory of sport is learning what we can do with the natural talents we have, perfecting them through admirable, persistent effort" [11] (p. 26). His characterization of sport places natural talent, excellence (perfection), and effort at the center of what sport is about, conferring more magnitude to the latter by referring to it as "admirable." Along these lines, in Good sport: Why our games matter and how doping undermines them, he argues that the meaning of sport is "the celebration of the variety of human talents" [16] (p. 13). That is to say, paraphrasing the title of his book, our games matter because they are sites for the cultivation of talent through effort. To explore the interrelationship among talent, effort, and ethical value in Murray's characterization of sport, the concepts of "talent" and "variety" must be analyzed in depth. With regard to the former, Murray claims that rules in sport are intended to restrict the participants' action to bring to light specific human talents. For instance, soccer rules forbid the use of hands to find out how talented people are at controlling a ball using any part of their body, the feet mostly, other than their hands. Similarly, to display people's speed and endurance talents, the rules of foot racing require to complete the track by running, barring wheeled or motorized means of transportation.

According to Murray, the concept of "variety," or "difference," plays a crucial role in three aspects of sport. First, different sports test various types of talents. For example, participants in a $100 \mathrm{~m}$ race test their talents for foot racing and speed, whereas participants in a car race test their driving and strategic thinking talents. However, sports are not tests of abilities only but also contests [17]. Sports involve competition. Participants confront each other to compare their performance and determine who is most talented. Competition, according to Murray, makes sport more engaging and becomes the second aspect of sport in which, he claims, difference plays a key role. Determining who is best is 
only possible if the exercise of natural talent generates different performance levels. For instance, if all participants in a foot race run at the same pace and crossed the finish line at the same time, the contest would fail to determine who is best, becoming less interesting. Third, sport rules discriminate among various ways to perfect human talents. For example, utilizing tactical innovations is accepted, whereas using pieces of equipment to which some participants have exclusive access is not.

In sum, ethical analyses of sport, according to Murray, must consist in examining "what ought to make a difference" in sport [16] (p. 62) by considering: (a) The talents tested in the game (nature of sport); (b) the way the competition determines who is best (nature of the competition); and (c) the means to develop talent (nature of sport performance). Anti-doping regulation mostly focuses on (c). Thus, Murray argues, "What we care about in sport is the combination of natural talents, dedication and discipline to perfect those talents, and the courage to test yourself against an external standard" [16] (p. 21, my emphasis) ${ }^{3}$. That is to say, differences tested in sport must result from the participants' "superior gifts and work ethics" [16] (p. 63). In his view, talent and work give meaning to sport. To support his "talentocratic" view of sport based on "the virtuous perfection of natural talent" [18] (p. 83), Murray argues that,

We want interesting contests, and we want athletes to be able to compete on a level playing field that is roughly level except for natural gifts, honed by dedication, that athletes bring to the competition. [16] (p. 24)

For him, sport acquires significance based on what "we" ${ }^{\prime 4}$ want it to be. "We" collectively determine the meaning of sport. To illustrate this point, he refers to the ban on polyurethane, full-body suits in swimming. When athletes started using such swimsuits, the number of records broken increased significantly. This alerted International Swimming Federation (FINA) officials, who, after investigating the performance-enhancing effects of the suits, banned them on the basis that they, in Murray's words, "threatened to change the meaning of the sport [by] rewarding muscled, stocky athletes who paddled on top of the water rather than sleek bodies slicing through it. The new swimsuits threatened to alter what swimming valued" [16] (p. 44). I take the phrase "what swimming valued" to mean "what the swimming community values." That is to say, in Murray's view, people's admiration for the exhibition of a specific set of natural talents confers value to the sport: "The achievement of athletes ... find their meaning and value in the celebration of whatever natural talents those persons bring to their sport" [16] (p. 56).

Performance-enhancing technology, like revolutionary swimsuits, poses a threat to what people value from sport. It undermines what they admire and celebrate by playing down the effort to develop natural talents. In alignment with this, Murray argues that, "people who play and love sport are uncomfortable with the use of performance-enhancing drugs [is that] the size of one's medicine cabinet doesn't fit into the picture [of] what we admire about athletic excellence." [16] (p. 52). Differences in sport performance, according to him, should not be the result of taking drugs because sports are not intended to test the effectiveness of drugs.

Loland and McNamee further elaborate on Murray's view of sport by linking the perfection of natural athletic talent to the cultivation of moral excellence. For them, unlike for Murray, sport does not acquire value mostly from the meaning that individuals attribute to it. Instead, it becomes valuable as a site for forging moral excellence. Thus, they argue:

3 This aligns with Pieter Bonte's claim that appeals to the "spirit of sport" principle to morally evaluate differences in sport performance based on (a) the origin of sport performance (natural); (b) the processes by which performance is perfected (dedication and discipline); and (c) its outcome (individuals' own performance) [18].

4 A clarification of what the term "we" stands for is needed. I take it to refer to the sporting community. However, this is still problematic for two reasons. First, it remains unclear who the members of such community are. Second, if as Murray argues, sport is a social good, then all members of a society, regardless of whether they are involved in sport, must be regarded as members of the sporting community. An in-depth investigation of who counts as a member of a practice community can be found in William J. Morgan's Leftist Theories of Sport [19]. 
Sport is a cultural practice in which human capabilities of particular performances are measured, compared, and ranked ... More generally, developing these capabilities is considered to lead towards moral development of the individual. [3] (p. 117)

A fundamental assumption in Loland and McNamee's "neo-Aristotelian" view, as they refer to it [3], is that dedication to the development of athletic excellence is connected to that of moral excellence. Drawing on the claim that sport can build character, they argue that the ethical assessment of performance-enhancing technology must focus on how such technology affects the promotion of excellence. For them, "enhancement and performance development has to take place in particular ways to enable development of virtue" [3] (p. 118). Thus, from their perspective, performance enhancement is morally problematic when it hinders the acquisition and development of virtue. In particular, when it undermines the importance of training and effort in perfecting athletic talent. Loland and McNamee acknowledge that the claim that training and effort lead to human excellence is, at the very least, controversial. Thus, they devote a significant part of their work to elaborate on it [20-22].

In "Performance-enhancing drugs, sport, and the ideal of natural athletic performance" [23] (p. 4), Loland builds upon Richard Norman's view of "nature" as a background of limitations that are not a matter of choice to argue that achievement in sport "gains significance" against constraints coming from two sources: Humans' bodily configuration and the logic of games. Such constraints, Loland points out, are absolute. That is to say, they are not matters of human choice, but given. Drawing on David C. Malloy and his collaborators' notion of "physiological authenticity" [24] (p. 294), Loland argues that humans share a, "phenotypic plasticity of the human organism as developed in evolution" [25] (p. 10). This phenotypic plasticity is essential to the cultivation of physical talent. For it is the basis of the processes "within the individual" that make enhancing performance possible [25] (p. 10). For instance, through training, athletes tackle and benefit from such processes by "expos[ing] the human organism to environmental stress, resulting in response and adaptation patterns from the molecular to the systemic level" [25] (p. 10). Performance-enhancing technologies, Loland points out, affect the body very differently. They "bypass human experience to work their biological 'magic' directly" (President's Council on Bioethics, 2003, 130 cit. in Loland, 2018, 12) by "produc[ing] a beneficial physiological effect in an athlete without invoking the complex organismal reaction described for the training stress response" [20].

Acknowledging that biological processes per se lack ethical value, Loland claims that bypassing the natural adaptation processes of the body eliminates, or negatively affects, valuable elements of sport performance. That is to say, despite being ethically neutral, biological processes are vital to the moral evaluation of sport performance. In particular, they provide a set of biological constraints that individuals must accept in order to exert their agency and effort. Thus, Loland argues that the removal of biological constraints threatens "athlete autonomy [and sport], as a measure of athletic effort and performance, loses its significance" [26] (p. 74). Agency and effort give value to sport. Performance-enhancing technology is morally problematic as it shifts the locus of performance from athletes to the technology on which they rely ${ }^{5}$. In Loland's words, "PEDs exert their performance-enhancing effect without real athlete insight and control" [28] (p. W2). Technology removes effort and, in turn, negatively affects the merit in athletic achievement. The concept of "merit" is key in Loland's assessment of performance-enhancing technology, for it connects biological constraints to those related to game play.

Loland, in alignment with Murray, regards sports as meritocratic activities intended to measure, compare, and rank participants based on "rule-defined abilities and skills" [25] (p. 10). Game rules

5 This position is widespread in the sporting community. For instance, the Lugano Charter issued by the Union Cycliste Internationale (UCI) declares that the technical aspects of bicycles must be controlled so that "[t]he performance achieved [does not depend] more on the form of the man-machine ensemble than the physical qualities of the rider, [which] goes against the very meaning of cycle sport" [27]. In cycling, as stated in the Charter, "The bicycle serves to express the effort of the cyclist, but there is more to it than that" [27]. 
limit the participants' scope of action to promote the cultivation of specific skills. In doing so, they set constraints that, like the biological ones, give significance to the practice. Better said, the obstacles to be overcome through sport-specific skills confer meaning to the practice. For instance, the rules of soccer limit the scope of skills exercised in the game to favor kicking, teamwork, and strategic thinking. Thus, soccer players engage in the sport for the sake of experiencing the development and exercise of such skills.

Elaborating on the centrality of skill exhibition in sport, Loland points out that rules emphasize the role skills play in the game by eliminating, or at least minimizing, the influence of factors over which participants have no control. Good games are those whose outcome is decided based on skillful performance for which individuals are responsible. To put it differently, for Loland, participants deserve to be recognized as better competitors than their opponents only when their performance results from their effort. According to Loland, athletes whose performance results from the use of performance-enhancing technology, "can no longer be identified clearly with the upper (and often decisive) edge of their performance" [25] (p. 12). If athletes cannot be identified with their superior performance, then they do not deserve to take credit for it.

In sum, for Loland, performance-enhancing technology is detrimental to sport because it bypasses the effort exerted to overcome artificial obstacles in the game and biological constraints evolutionary developed. In other words, sport is valuable as a site to exert effort to develop inborn talents and overcome challenges. Effort is the normative cornerstone of competitive sport. Thus, Loland claims, "elite sport ... is better conceived of as a moral testing ground. Athletes are challenged not only on their sporting abilities and skills, but on their values" [25] (p. 12). Engagement in sports is valuable for its role in helping individuals hone excellences and build character. Differently put, sports are valuable as a means to acquire (physical and moral) excellence.

\section{What Concept of Human Nature Underpins WADA's "Spirit of Sport" Criterion? Protestantism, Anti-Doping, and Human Nature}

Sport historians and sport philosophers argue that the value attached to effort in sport emerged within a specific view of the world, namely, that of the Protestant ethic and, in turn, modern capitalism ${ }^{6}$. For instance, Verner Møller, drawing on Max Weber's [30] analysis of modernity, argues that the emphasis on effort and work that characterizes modern sport has its origin in the Protestant notion of "calling" or "vocation" [31] (p. 104). The Protestant approach to life is built upon the idea that individuals' fate, that is, whether they will obtain salvation, is decided from birth. Despite this, they search for signs that indicate "whether [they are] saved or dammed" [32] (p. 524). Good works are such signs. Through them, Protestants acquire evidence and assurance of salvation.

Luther and Calvin connect the effort to do good works to the notion of "calling" or "vocation." They regard good works as duties that God has appointed to humans. For instance, Luther states, "The Gospel ... requires that ... each according to his own calling, manifest Christian love and genuine good works in his station of life" [33] (p. 145), and Calvin says, "every one should be contented with his calling, and pursue it, instead of seeking to betake himself to anything else. A calling in Scripture means a lawful mode of life" [34].

Each individual has their own line of life, that is, specific duties pertaining to their calling. Thus, doing good works involves fulfilling the duties that God has appointed to them. This does not imply that individuals are fully determined to stick to a specific role in life. Rather, they are free to choose their own path, as long as it involves fulfilling the duties attached to the calling, namely: Serving God and engaging in productive enterprises with diligence. In alignment with this, Calvin states:

6 Despite the strong connection between Protestant ethic and the ethos of modern sport, Allen Guttmann, in his seminal analysis of the origins of modern sports, From ritual to record. The nature of modern sports, argues that, the emergence of modern sports represents neither the triumph of capitalism nor the rise of Protestantism but rather the slow development of an empirical, experimental, mathematical Weltanschauung [(worldview)] [29] (p. 85). 
Farther, he calls every one to this rule also-that they bear in mind what is suitable to their calling. He does not, therefore, impose upon any one the necessity of continuing in the kind of life which he has once taken up, but rather condemns that restlessness, which prevents an individual from remaining in his condition with a peaceable mind and he exhorts, that every one stick by his trade. [34]

The emphasis on fulfilling the duties of one's calling or vocation leads to the glorification of work, the virtues related to it, and, especially, its outcomes (i.e., production, wealth, ownership, and profit). This is illustrated by Thomas Carlyle's dictum, "The latest Gospel in this world is, 'know thy work and do it'" [35] (p. 244). Individuals must take their calling seriously and work with diligence to fulfill their duties. In turn, unproductive behavior that distracts individuals from working or, in Steven J. Overman's words, "from serious and useful activities" [36] (p. 30) is vilified. Therefore, any activity engaged in for the sake of enjoyment, with no further purpose or higher goal, is condemned and regarded as trivial, non-serious, or "time-wasting." Trivial activities are related to idleness, play, and pleasure, which are accepted only when subordinated to social labor or the achievement of a higher purpose.

Sport, from a Puritan perspective, is embraced as preparation for labor or, like in Victorian English schools, as a means to build people's character. In his study on Puritanism and sport, Heinz Mayer argues, "Puritanism regarded sport as a help in shaping one's life, in conserving health, in developing and forming character" [37]. Along these lines, in his seminal autobiography, C. L. R. James explains how his engagement in cricket affected his character in the following way: "almost entirely by my own efforts, I mastered thoroughly the principles of cricket ... and attained a mastery over my own character which would have done credit to my mother and Aunt Judith" [38] (pp. 23-24). Understanding the reference to his mother and aunt is crucial here. For throughout the book, both are portrayed, especially his aunt, as living illustrations of the Protestant ethic.

Protestants see life as a series of "problems to be solved" [36] (p. 22) in order to become successful through, among other activities, profit-making and ownership. To do so, they must embody an "innerworldly ascetic" attitude consisting in self-discipline. This explains why the Protestant attitude favored the development and triumph of capitalism. For not only did it turned profit-making and economic (instrumental) rationality into the main drivers of people's action, but also into means for acquiring social status and affirming human worth. Devotion to work, productivity, and human worth are intertwined in the Protestant ethic. In Overman's words, “The spirit of capitalism didn't imply a greater love of money; its real import was in the drive to acquire money and the moral value attached to its acquisition" [36] (p. 49). The devotion to work in order to become successful, not the enjoyment of the outcome of work, defines Protestantism. Thus, Protestants demand abstinence and self-cultivation and condemn gratification pursued for its own sake. The following claim by the main character in George Santayana's novel, The Last Puritan, perfectly illustrates Protestants' attitude towards pleasure and gratification: "I hate pleasure. I hate what is called having a good time" [39] (p. 371).

In the historic progress of modern society, the main elements of the Protestant ethic became secularized. Religious motivation and practices receded to the background. Mundane concerns superseded supernatural preoccupations. However, the Protestant ascetic way of life persevered through secular practices and motivation inherent to the modern work ethic that prevails in today's capitalist society. Labor is one such activity; sport is another. In the factory and sport field, work and effort remain to be regarded as the primary sources of value. Moreover, work and sport have become characterized by the same elements at defining the Protestant ethic, to wit: Self-reliance, compulsive behavior towards work, perfectionism, a sense of responsibility for improving one's skills, excelling, overcoming obstacles, delayed gratification, striving, and competing [36] (p. 57). Interestingly, sport winded up becoming a better site for cultivating the work ethic, as technological progress increasingly resulted in the automatization of laborious manual tasks, reducing the level of difficulty found in labor activities. As Overman argues, 
Sport provided a counterweight to the existential impoverishment of work. [T]hrough the natural motions of sport, the stifled artisan was able to rediscover activities in which he could compete against himself, manipulate innate forces, and actively execute the craftsman-like skills inherent to traditional work. [36] (pp. 133-134)

Sport became the new outlet of the Protestant spirit. The Protestant view of human nature as something given that must be accepted and improved through effort and work to become successful underpins the restrictive view of sport that characterizes sport in terms of struggle for excellence, overcoming obstacles, suffering, discipline, and skill development. Baron Pierre de Coubertin's formulation of Olympism as a "philosophy of life" [8] (p. 13) focused on the cultivation of excellence to achieve a higher purpose (i.e., harmonious development of humankind and peace). This facilitated the transformation of the values inherent to the modern work ethic into concepts to think about and conceptualize modern sport. Furthermore, given the role the IOC played in the creation of WADA, it is apparent that the work-related ethical principles underpinning Olympism have shaped the doping public debate and anti-doping policy significantly.

In sum, like the IOC and WADA, Murray's, Loland's, and McNamee's view of sport and human nature revolve around the values inherent to the modern work ethic. As it has been shown in Sections 2 and 3, the three philosophers above emphasize the need to eliminate luck and chance to favor skill development and effort through training. They also regard technological means that undermine the role of effort and work as morally dubious. Such technologies are undesirable shortcuts and signs of the weakness of the will and lack of moral fiber [31] (p. 105). Moreover, they ground the normative value of sport in higher goals such as building character and promoting social goods. Therefore, the work ethic and its notion of human nature have had a strong influence on the views of sport held by WADA and the philosophers who have been instrumental in justifying the anti-doping movement. Their view of what is natural in sport is connected to the protection of the value of the athletes' effort to become successful through the acceptation of what has been given to them.

\section{Challenging the "Effort-Based" View of Sport Underpinning WADA's Justification of Anti-Doping}

In this section, I will pose critical questions that proponents of the restrictive view of sport at the heart of anti-doping must address to strengthen their position.

\subsection{Why are Hard Work, Effort, and Excellence the Normative Cornerstones of Sport and Anti-Doping?}

The restrictive view of sport builds upon a view of human nature founded on the value of work. However, as R. Scott Kretchmar argues [40] (p. 46), pluralism, instead of monism, seems to best capture the debate on the nature of sport. According to him, there are multiple interpretations of human nature and sport, including elite-level sport. In particular, the notions of sport vary depending on the degree to which they embody the following six aspects: (a) Achievement, (b) serendipity, (c) knowledge, (d) aesthetic value, (e) authenticity, and (f) community. For Kretchmar, these aspects of sport "are not free standing species or types of sport [but rather] normative emphases that can be realized in [sports]" [40] (p. 86). That is to say, multiple types of sport can be built upon one or several of them. Analyzing each of the aspects is beyond the scope of this paper. Nevertheless, I will offer several examples of how sport practices might be modulated differently depending on the emphasis placed on some aspects.

Consider first high school sport, which I regard as a version of sport that embodies most of, if not all, the aspects. As described in the National Federation of State High School Associations (NFHS) Mission Statement, sport at the high-school level,

enriches the educational experience; encourages academic achievement; promotes respect, integrity and sportsmanship; prepares for the future in a global community; develops leadership and life skills; fosters the inclusion of diverse populations; promotes healthy 
lifestyles and safe competition; encourages positive school/community culture; and should be fun. [41]

Drawing on Kretchmar's six aspects of sport [42], high-school sport is an arena for (a) seeking temporary relief from everyday life obligations by presenting individuals with interesting artificial problems to be overcome (serendipity); (b) finding out who one is by testing one's abilities (knowledge); (c) experiencing uncertainty and pleasure experiences derived from overcoming challenges and testing one's skills (aesthetic); and (d) engaging in a cooperative enterprise with others and realizing that individuals are always inextricably tied to others (community).

Similar statements can be found in governing bodies that regulate elite-level sport. For instance, for the National Collegiate Athletic Association (NCAA), the core values to be embodied by college sports are: pursuit of athletic and academic excellence, enhancing the sense of community, ethical leadership, and respect for the others. Likewise, since June 2007, the Fédération Internationale de Football Association's (FIFA) motto has become "For the Game. For the World." These goals significantly differ from, and often clash with, other goals pursued by most elite-level, professional sporting institutions. For instance, the Chicago Bulls Mission Statement states:

The Chicago Bulls organization is a sports entertainment company dedicated to winning NBA Championships, growing new basketball fans, and providing superior entertainment, value and service. [43]

Professional sport seen in this way is primarily built upon the achievement principle, that is, upon the pursuit of victory and financial success. This aligns with the most widespread view of professional sport as a meritocratic activity whose main goal is to strive for (and ultimately achieve) victory.

Yet, even among those who understand sport merely based on the achievement principle, there is disagreement about the nature of sport. For instance, in soccer, there are two opposing views on what the sport is about and, more importantly, how it should be played. One view defines soccer based on the deployment of passing skills to control the pace of the game (through possession) and score in a highly aesthetically pleasing way. This play style is referred to as "jogo bonito" or "beautiful play style" [44]. The other view is more pragmatic. Regarding victory as the most important thing, proponents of pragmatic soccer rely on strategic thinking to control every aspect of the game and find the most effective, not the most beautiful, way to score. Defenders of this soccer style call it "humble play style" or "smart play style" [45]. In sum, at the very least, there are two conflicting views in professional soccer, that of the poets and that of the workers, and proponents of each of them claim theirs as the best interpretation of soccer.

Given the plurality of views and essential aspects of sport, it is worth asking why anti-doping is built around the principles of hard work and excellence instead of other valuable elements such as idleness, excitement, self-knowledge, or joy. Proponents of the work-based (restrictive) view of sport might provide the following answers. First, drawing on the philosophical theory of sport called "broad internalism" or "interpretivism," they might argue that the "protection and promotion of the excellences of sport" [46] through hard work understands professional, competitive sport in its best light. This, after all, is the type of sport governed by anti-doping regulations. Second, they might argue that work and effort are two of the main pillars of contemporary society. Thus, the key role both elements play in sport, especially at the professional level, is a reflection of the dominance of such principles in the larger society. This claim aligns with the conventionalist view of sport, which takes sports to be social practices created to fulfill basic social and psychological needs that change through time. In modern society, thus, such needs have to do with the feelings of fulfilment, self-realization, and well-being derived from the value modern individuals place in work.

Against these responses, it can be argued that thinking about the nature of sport in terms of excellence might not reflect the most prevalent view of sport nowadays, that is, the view that prioritizes victory. In a different vein, if the restrictive view of sport aims to criticize the view of sport most prevailing among professionals, they could deploy alternative, more critical views of sport. For 
instance, sport could be a more "revolutionary, critical, or utopian social practice" if its goal was to subvert and challenge the main driving forces in the contemporary society, that is, the dominance of the work ethic. Indeed, philosophers Peter Sloterdijk [47], Brian O'Connor [48], and Suits [49], among others, defend that ludic activities such as sport could be shaped to instill a post-work attitude towards life.

\subsection{Could Anti-Doping be Grounded in an Assumption for Which Evidence is Less Ambiguous?}

Despite being widely accepted (and utilized) in the sporting world, philosophers have questioned the claim that athletic excellence and moral character are connected, especially in the context of professional, competitive sport. For instance, Allan Bäck agrees that sport is a site for developing some sort of skills and abilities, which athletes might come to excel. However, he wonders what such excellences entail. According to him, most sport excellences (e.g., putting a ball in a hole or running a ball up and down a field) are confined within the limits of sport itself. Thus, he argues, such excellences "even if attained, may thereby, for many people, be restricted to this artificial setting with its artificial rules." [50] (p. 225).

Bäck appeals to historical and psychological evidence to strengthen his critique and cast doubt on the connection between sport excellence and moral character. While he agrees that sports might have had positive effects on moral character, the opposite is also the case, especially in professional sports. For instance, he argues that, throughout history, sport has helped promote and perpetuate violent, dangerous, corruptive, and discriminatory behaviors. This is specially the case, his argument goes on, when victory becomes too important, as in modern professional sports. There seem to be intrinsic negative moral elements to sport. Even if these were eliminated, so that sport only promoted positive moral aspects, Bäck remains skeptical about the connection between moral behavior in sport and outside of it.

Psychological evidence on the transference of habits and values acquired in sport into other areas and contexts of life motivates his skepticism [50] (p. 226). He argues that, "often skills acquired in one role or social setting do not in general transfer: a person trained in critical thinking problems may continue to commit the same fallacies in other areas of her life." [50] (p. 226). Sport, according to him, is especially vulnerable to this problem because of the artificial nature of sport activities. Moreover, doubts about sports' positive effect on moral character are raised by psychological studies on the nature of competition and sport. Studies in moral psychology and group dynamics show that people invested in sport operate within an "in-group and out-group" mental framework that blinds them to moral status of individuals that belong to or are connected to rival sporting communities [51]. Similarly, studies on moral character and personality based on quantitative methods, such as the MMPI (Minnesota Multiphasic Personality Index) and the JPI (Jackson Personality Inventory), conclude that athletes do worse on these scales than non-athletes.

Sport philosophers such as David Carr [52] and Russell Gough [53] play down the validity of empirical studies of moral development. They argue that, in order to operationalize and quantify moral development, psychologists reduce the complexity of ethical concepts. However, such a methodological simplification undermines the project of understanding moral behavior. Mike McNamee adopts a similar but more moderate approach [22]. He agrees with the core of Carr's and Gough's critique of moral psychology, but advocates for a different solution, namely, the collaboration between psychologists and philosophers to overcome the limitations identified. Thus, for him, the attempt to ground the connection between sport excellences and moral character in empirical evidence is not fundamentally flawed and doomed to fail but "yet to be revealed" [22] (p. 86), that is, requires further research. According to him, philosophical analyses of moral development and judgment suffice to provide good reasons for upholding to the connection between sport excellences and moral character.

While I agree with McNamee's claims, I wonder if anti-doping policy, which affects thousands of athletes, should appeal to a notion for which empirical evidence remains relatively scarce and "yet to be revealed." To be clear, my claim here is neither that sport has no pedagogical effect, nor that philosophy 
has no say in policymaking. Quite the contrary. Like McNamee, I think that philosophical reasons suffice to support claims regarding moral development and that sport has the potential to shape moral judgment, at least to some extent. My claim concerns the grounds of policymaking. A policy can perform its role satisfactorily if it is regarded as justified by those whose behavior is governed by the policy. Policies that are viewed as lacking justification result in dissension, opposition, disobedience, and, in some cases, violence.

As Giandomenico Majone [54] argues, the existence of multiple views (pluralism) is a major challenge for policy justification. In social practices where multiple views coexist, Majone posits, multiple policy evaluation criteria must be deployed. In his words, "multiple policy evaluation ... would recognize the legitimacy of the different perspectives [and would] contribute to the shared understanding of the multiple perspectives involved" [54] (p. 9). For this reason, given the limitations of the empirical evidence supporting the connection between sport and character development, anti-doping regulation must not appeal to such a connection until further evidence is provided. A regulation with profound implications in people's lives such as anti-doping (e.g., athletes can lose the career to which they have devoted their lives as a consequence of an anti-doping sanction) must be built upon a firmer and broader foundation. Such a foundation can be provided through concepts such as health, primary goods, consent, justice, and autonomy. Although the nature of these concepts might be difficult to pin down fully and completely, there is consensus in the contemporary society on their validity to support policies affecting everybody.

\subsection{Are the Excellences Acquired Through Effort and Hard Work More Valuable than Those Resulting from other Aspects of Sport?}

Even if empirical evidence supported the connection among athletic excellence, moral excellence, and normative value, devoting effort to refining natural talents would not be the only source of moral value in sport. Rather, the cultivation of aspects other than effort might also shape character positively. The restrictive view of sport does not capture the meaning of sport in general, but of a particular formulation of sport. For instance, according to Savulescu [55], taking risks to push human limits further is morally praiseworthy and leads to the development of moral virtues such as courage. In a different work [56], I referred to this view of sport as "posthumanist." This view, unlike the restrictive view of sport, builds upon a notion of human nature that denies the possibility of providing a clear-cut distinction between natural and artificial aspects. In this view, not only is technology inherent to human nature, but it realizes the aspect that best defines humans, namely: autonomy. Thus, doping is regarded as a means for exercising freedom [4]. This view conceives of the source of moral value in sport in relation to the notion of human nature and sport defined based on the exercise of freedom, not the effort in developing natural talents. Therefore, posthumanists might also argue that a source of value in sport is the cultivation of excellence and the forge of moral character but might interpret the latter in a significantly different way from those in the restrictive side.

Moreover, according to Sinclair A. MacRae, "defenders [of the view that excellence has normative value] would need to show both that excellence can function as a foundational or overarching goal and that it is an ethical value. However, neither of these claims is true" [57] (p. 292). For MacRae, excellence is neither a moral nor a prudential value but a perfectionist value that requires an objective standard of perfection. Therefore, if different views of sport, such as the posthumanist and the restrictivist, hold diverse standards of perfection, then rational agreement on what athletic excellence is would be difficult to achieve, if not impossible. With regard to rational disagreement, Alasdair MacIntyre [58] argues that each tradition holds its view of the good that can only be rationally accepted by those within the tradition, because they share a basic set of standards of rationality. As individuals only understand the notion of the good by being part of a particular tradition, MacIntyre argues that traditions and their standards are incommensurable with each other. Thus, rational discussion and agreement among them is uncommon. William J. Morgan draws on MacIntyre and, regarding the anti-doping debate, argues that there are other views of sport besides the work-based view that WADA holds [59] (p. 289). For 
instance, professionalism, whose advocates view sport as a meritocratic activity open to talent where the pursuit of victory plays a central role, and "transhumanist sport," which builds upon the notion that sport is a site for pushing the limits of human nature further by deploying technological means. A transhumanist, for example, as I have stated above, world regard a performance as excellent when an athlete sets a new record or standard within a sport (i.e., completing a marathon in under one hour).

\subsection{A Consensus around a Common View of Sport?}

In sum, given the plurality of conceptions of human nature and sport in the contemporary society, there is disagreement around the justification for anti-doping policy. If the view of human nature at the root of the different views of sport is the fundamental source of disagreement, I wonder if it would be possible to find, in Rawls' terms, an "overlapping consensus on a common minimal view of human nature or sport" [60]. Here I draw a parallel between the debate on the nature of sport and that of modern society. The coexistence of multiple worldviews is the defining mark of modern societies. Thus, pluralism and moral disagreement are the norm, not something to avoid and correct. The challenge modern ethical theories face is to create and organize social cooperation irrespective of people's individual conceptions of the good life, assuming that most people would not agree on what the good is. One possible solution to the problem of cooperation has been provided by Kantian-inspired "thin moral (or political) theories." Based on the fact all human beings share some feature/s in common, Kantian-inspired approaches claim that people have the potential to agree on a basic set of minimal ethical principles to arrange cooperation. Therefore, a possible solution to the doping debate might be to provide a Kantian-inspired thin moral theory of sport that focuses on features that all sport participants share in common in order to make cooperation possible by resolving the existing moral disagreement on the nature of sport. That is to say, contemporary sport philosophers should explore the possibility of providing a "shallow (or thin) model of sport" [61]. Indeed, Loland and McNamee might lead the way in this respect. In a recent paper, they wonder whether "references to 'the spirit of sport' [can] serve as basis for an overlapping consensus among all stakeholders in the anti-doping domain" [62] (p. 7), and offer an alternative formulation of the "spirit of sport" principle that might facilitate the achievement of such a type of consensus: "The purpose of anti-doping policy and practice is to preserve and promote the committed pursuit of athletic excellence in ways that respect the health of athletes and the integrity of sport competition" [62] (p. 11). Their formulation of the "spirit of sport" principle, however, still pivots around the concept of "excellence," which is problematic. Elsewhere, I explore an alternative to achieve overlapping consensus among different sport traditions [63]. Drawing on discourse ethics, I propose that philosophers should focus less on the specific content of sport regulations and more on the structure and conditions of the deliberative and decision-making practices whereby such regulations are discussed, formulated, and accepted. This focuses the sport philosophers' attention on the real debates around normative aspects of sport that take place within sport institutions and recommends philosophers to work with institutions in creating and structuring deliberative spaces for individuals to engage in rational discussion and collectively pursue rational consensus [64].

\section{Conclusion: Anti-Doping, the Work Ethic, and the Natural}

I have examined the "spirit of sport" criterion on which WADA relies to justify the ban on performance-enhancing technologies. By analyzing the connection between anti-doping and the notion of the "natural," I have identified the view of human nature that underpins the "spirit of sport" criterion. By reviewing WADA's official documents and scholarly works articulating the WADA's notion of the "spirit of sport," I have shown that WADA's justification for anti-doping has its roots in the notion of human nature of the work ethic that resulted from the secularization of the Protestant ethic. I have concluded by raising the following critical questions concerning the view of human nature and sport at the basis of WADA's justification of anti-doping:

- Why are hard work, effort, and excellence the normative cornerstones of sport and anti-doping?

- Could anti-doping be grounded in an assumption for which evidence is less ambiguous? 
- Are the excellences acquired through effort and hard work more valuable than those resulting from other aspects of sport?

My tentative response to these questions has been that there is plurality of views of sport nowadays. Therefore, anti-doping must not be built upon any of them, but upon a "shallow (or thin) model of sport" that all sport participants can accept regardless of their specific view of human nature and sport. Providing such a model of sport is one of the main challenges that contemporary sport philosophers must face.

Funding: This research received no external funding.

Conflicts of Interest: The author declares no conflict of interest.

\section{References}

1. Schiappa, E. Defining Reality: Definitions and the Politics of Meaning; Southern Illinois University Press: Carbondale, IL, USA, 2003; ISBN 978-0-8093-2500-9.

2. Nuffield Council on Bioethics (Un)natural. Ideas about Naturalness in Public and Political Debates about Science, Technology and Medicine; Nuffield Council on Bioethics: London, UK, 2015.

3. Loland, S.; McNamee, M.J. Anti-doping, performance enhancement and 'the spirit of sport': A philosophical and ethical critique. In Doping and Public Health; Ahmadi, N., Ljungqvist, A., Svedsäter, G., Eds.; Routledge: London, UK, 2016; pp. 111-123.

4. Brown, W.M. Ethics, drugs, and sport. J. Philos. Sport 1980, 7, 15-23. [CrossRef]

5. Savulescu, J.; Foddy, B.; Clayton, M. Why we should allow performance enhancing drugs in sport. Br. J. Sports Med. 2004, 38, 666-670. [CrossRef]

6. Miah, A. Genetically Modified Athletes: Biomedical Ethics, Gene Doping and Sport; Routledge: New York, NY, USA, 2004; ISBN 1-134-42599-6.

7. World Anti-Doping Agency (WADA). World Anti-Doping Code 2015. Available online: https://www.wadaama.org/sites/default/files/resources/files/wada-2015-world-anti-doping-code.pdf (accessed on 22 June 2019).

8. International Olympic Committee (IOC). Olympic Charter 2015. Available online: https://stillmed.olympic. org/Documents/olympic_charter_en.pdf (accessed on 22 June 2019).

9. Dunn: Dopers Must Stay Away from London 2012 (24 February 2012). Available online: https://www.wada-ama. org/en/media/news/2012-02/dunn-dopers-must-stay-away-from-london-2012 (accessed on 23 January 2019).

10. Koji Murofushi-Why the Spirit of Sport Must be Maintained (22 September 2014). Available online: https://www.wada-ama.org/en/media/news/2014-09/koji-murofushi-why-the-spirit-of-sport-mustbe-maintained (accessed on 23 January 2019).

11. Murray, T.H. Ethics, enhancement, and sport. Play True: Off. Publ. World Anti-Doping Agency 2007, 24-32.

12. McNamee, M.J. The Spirit of Sport and Anti Doping Policy: An Ideal Worth Fighting for. Available online: https://www.wada-ama.org/en/media/news/2013-02/the-spirit-of-sport-and-anti-doping-policy-anideal-worth-fighting-for (accessed on 23 January 2019).

13. Borry, P.; Caulfield, T.; Estivill, X.; Loland, S.; McNamee, M.; Knoppers, B.M. Geolocalisation of athletes for out-of-competition drug testing: Ethical considerations. Position statement by the WADA ethics panel. Br. J. Sports Med. 2018, 52, 456-459. [CrossRef]

14. Murray, T. Sports Enhancement. Available online: https://www.thehastingscenter.org/briefingbook/sportsenhancement/ (accessed on 23 January 2019).

15. WADA Ethics Panel. Available online: https://www.wada-ama.org/en/who-we-are/governance/wada-ethicspanel (accessed on 23 January 2019).

16. Murray, T.H. Good Sport. Why Our Games Matter and How Doping Undermines Them; Oxford University Press: New York, NY, USA, 2018; ISBN 978-0-19-068798-4.

17. Kretchmar, R.S. From test to contest: An analysis of two kinds of counterpoint in sport. J. Philos. Sport 1975, 2, 23-30. [CrossRef]

18. Bonte, P. Dignified doping: Truly unthinkable? An existentialist critique of "talentocracy" in sports. In AthleticEnhancement, Human Nature and Ethics: Threats and Opportunities of Doping Technologies; Tolleneer, J., Sterckx, S., Bonte, P., Eds.; Springer: Dordrecht, The Netherlands, 2013; pp. 59-86, ISBN 94-007-5101-X. 
19. Morgan, W.J. Leftist Theories of Sport: A Critique and Reconstruction; University of Illinois Press: Champaign, IL, USA, 1994; ISBN 0-252-06361-9.

20. Loland, S.; Hoppeler, H. Justifying anti-doping: The fair opportunity principle and the biology of performance enhancement. Eur. J. Sport Sci. 2012, 12, 347-353. [CrossRef]

21. Loland, S. A well balanced life based on 'the joy of effort': Olympic hype or a meaningful ideal? Sport Ethics Philos. 2012, 6, 155-165. [CrossRef]

22. McNamee, M. Sports, Virtues and Vices: Morality Plays; Routledge: New York, NY, USA, 2008; ISBN 1-134-64978-9.

23. Norman, R. Interfering with nature. J. Appl. Philos. 1996, 13, 1-12. [CrossRef] [PubMed]

24. Malloy, D.C.; Kell, R.; Kelln, R. The spirit of sport, morality, and hypoxic tents: Logic and authenticity. Appl. Physiol. Nutr. Metab. 2007, 32, 289-296. [CrossRef] [PubMed]

25. Loland, S. Performance-enhancing drugs, sport, and the ideal of natural athletic performance. Am. J. Bioeth. 2018, 18, 8-15. [CrossRef]

26. Loland, S.; Caplan, A. Ethics of technologically constructed hypoxic environments in sport. Scand. J. Med. Sci. Sports 2008, 18 (Suppl. 1), 70-75. [CrossRef]

27. UCI. The Lugano Charter 1996. Available online: http://62.50.72.82/imgArchive/Road/Equipment/The\% 20Lugano\%20charter.pdf (accessed on 20 June 2019).

28. Loland, S. Response to open peer commentaries on "performance-enhancing drugs, sport, and the ideal of natural athletic performance". Am. J. Bioeth. 2018, 18, W1-W3. [CrossRef]

29. Guttmann, A. From Ritual to Record: The Nature of Modern Sports; Columbia University Press: New York, NY, USA, 1978; ISBN 978-0-231-08369-0.

30. Weber, M. The Protestant Ethic and the Spirit of Capitalism; Unwin Paperbacks: London, UK, 1985.

31. Møller, V. The Ethics of Doping and Anti-Doping: Redeeming the Soul of Sport? Routledge: London, UK, 2010; ISBN 978-0-415-48465-7.

32. Parsons, T. The Structure of Social Action: A Study in Social Theory with Special Reference to a Group of Recent European Writers; Amerind: New Delhi, India, 1974.

33. Gritsch, E.W.; Jenson, R.W. Lutheranism: The Theological Movement and Its Confessional Writings; Fortress Press: Philadelphia, PA, USA, 1976.

34. Calvin, J. John Calvin's Bible Commentaries on St. Paul's First Epistle to the Corinthians; Jazzybee Verlag: Altenmünster, Germany, 1989.

35. Carlyle, T. Past and Present; Chapman and Hall: London, UK, 1870.

36. Overman, S.J. The Protestant Ethic and the Spirit of Sport: How Calvinism and Capitalism Shaped America's Games; Mercer University Press: Macon, GA, USA, 2011; ISBN 978-0-88146-226-5.

37. Meyer, H. Puritanism and physical training: Ideological and political accents in the Christian interpretation of sport. Int. Rev. Sports Soc. 1973, 8, 37-52. [CrossRef]

38. James, C.L.R. Beyond a Boundary; Stanley Paul: London, UK, 1976.

39. Santayana, G. The Last Puritan; Scribner: New York, NY, USA, 1937.

40. Kretchmar, R.S. Simon on realism, fallibilism, and the power of reason. J. Philos. Sport 2016, 43, 41-49. [CrossRef]

41. National Federation of State High School Associations (NFHS). Mission Statement. Available online: https://www.nfhs.org/who-we-are/missionstatement (accessed on 4 March 2019).

42. Kretchmar, R.S. Pluralistic internalism. J. Philos. Sport 2015, 42, 83-100. [CrossRef]

43. Chicago Bulls Mission Statement. Available online: https://www.nba.com/bulls/news/mission_statement. html (accessed on 4 March 2019).

44. McLaughlin, D.W.; Torres, C.R. Sweet tension and its phenomenological description: Sport, intersubjectivity and horizon. Sport Ethics Philos. 2011, 5, 270-284. [CrossRef]

45. Wilson, J. Inverting the Pyramid: A History of Football Tactics; Orion: London, UK, 2008.

46. Russell, J.S. Are rules all an umpire has to work with? J. Philos. Sport 1999, 26, 27-49. [CrossRef]

47. Sloterdijk, P. Good-for-nothing returns home. Or the end of an alibi-And a theory of the end of art. In The Aesthetic Imperative: Writings on Art; Polity: Malden, MA, USA, 2017; pp. 100-112, ISBN 978-0-7456-9986-8.

48. O'Connor, B. Idleness: A Philosophical Essay; Oxford Princeton University Press: Princenton, NJ, USA, 2018; ISBN 978-0-691-16752-7.

49. Suits, B. The Grasshopper: Games, Life, and Utopia; D.R. Godine: Boston, MA, USA, 1978; ISBN 978-0-87923-840-7. 
50. Bäck, A. The way to virtue in sport. J. Philos. Sport 2009, 36, 217-237. [CrossRef]

51. Lopez Frias, F.J. The psycho-biological bases of sports supporters' behaviour: The virtuous supporter. Sport Ethics Philos. 2012, 6, 423-438. [CrossRef]

52. Carr, D. What moral education significance has physical education? A question in need of disambiguation. In Ethics and Sport; McNamee, M., Parry, S.J., Eds.; Routledge: New York, NY, USA, 2016; pp. 119-133, ISBN 978-1-138-14197-1.

53. Gough, R. Moral development research in sports and its quest for objectivity. In Ethics and Sport; McNamee, M., Parry, S.J., Eds.; Routledge: New York, NY, USA, 2016; pp. 134-147, ISBN 978-1-138-14197-1.

54. Majone, G. Evidence, Argument, and Persuasion in the Policy Process; Yale University Press: New Haven, CT, USA, 1989; ISBN 978-0-300-04159-0.

55. Savulescu, J. Justice, fairness, and enhancement. Ann. N. Y. Acad. Sci. 2006, 1093, 321-338. [CrossRef] [PubMed]

56. Lopez Frias, F.J. Walking into the cyborg gym. Two conceptions of the cyborg athlete. Teknokult. Rev. Cult. Digit. Mov. Soc. 2018, 15, 105-117. [CrossRef]

57. MacRae, S.A. Toward a shallow interpretivist model of sport. J. Philos. Sport 2017, 44, 1-15. [CrossRef]

58. MacIntyre, A.C. After Virtue: A Study in Moral Theory; University of Notre Dame Press: Notre Dame, IN, USA, 1984.

59. Morgan, W.J. The normativity of sport: A historicist take on broad internalism. J. Philos. Sport 2016, 43, 27-39. [CrossRef]

60. Rawls, J. Justice as Fairness: A Restatement; The Belknap Press of Harvard University Press: Cambridge, UK; London, UK, 2001; ISBN 978-0-674-00510-5.

61. Lopez Frías, F.J. A critique of mutualism's combination of the Aristotelian and Kantian traditions. J. Philos. Sport 2018, 45, 161-176. [CrossRef]

62. Loland, S.; McNamee, M.J. The 'spirit of sport,' WADAs code review, and the search for an overlapping consensus. Int. J. Sport Policy Polit. 2019, 1-13. [CrossRef]

63. Lopez Frías, F.J. Beyond Habermas, with Habermas: Adjudicating ethical issues in sport through a discourse ethics-based normative theory of sport. Sport Ethics Philos. 2019, in press.

64. Read, D.; Skinner, J.; Lock, D.; Houlihan, D. Legitimacy driven change at the World Anti-Doping Agency. Int. J. Sport Policy Polit. 2018, 1-13. [CrossRef] 